\title{
A Survey of Anxiety and Depressive Symptoms in Pulmonary Tuberculosis Patients With and Without Tracheobronchial Tuberculosis
}

\author{
Xiao-bo Wang ${ }^{1+}$, Xue-lian $\mathrm{Li}^{2 \dagger}$, Qing Zhang ${ }^{3}$, Juan Zhang ${ }^{4 *}$, Hong-yan Chen ${ }^{4}$, \\ Wei-yuan $X^{5}{ }^{5}$, Ying-hui Fu' ${ }^{6}$, Qiu-yue Wang ${ }^{1}$, Jian Kang ${ }^{1}$ and Gang Hou ${ }^{1 *}$ \\ ${ }^{1}$ Department of Respiratory Medicine, The First Hospital of China Medical University, Shenyang, China, ${ }^{2}$ Department of \\ Epidemiology, School of Public Health, China Medical University, Shenyang, China, ${ }^{3}$ Department of Endoscopy, Shenyang \\ Thoracic Hospital, Shenyang, China, ${ }^{4}$ Department of Laboratory, Shenyang Thoracic Hospital, Shenyang, China, \\ ${ }^{5}$ Department of Respiratory Medicine, Anshan Central Hospital, Anshan, China, ${ }^{6}$ The Fourth Department of Tuberculosis, \\ Shenyang Thoracic Hospital, Shenyang, China
}

OPEN ACCESS

Edited by:

Gianluca Serafini,

Ospedale San Martino (IRCCS), Italy

Reviewed by:

Casimiro Cabrera Abreu, Queens University, Canada Annika Sweetland,

Columbia University, United States

*Correspondence:

Gang Hou

hougangcmu@163.com

Juan Zhang

zhangjuansyth@163.com

tThese authors have contributed equally to this work.

Specialty section: This article was submitted to Mood and Anxiety Disorders, a section of the journal Frontiers in Psychiatry

Received: 27 July 2017 Accepted: 20 June 2018 Published: 19 July 2018

Citation:

Wang X, Li X, Zhang Q, Zhang J, Chen $H, X u$ W, Fu Y, Wang $Q$, Kang J and Hou G (2018) A Survey of Anxiety and Depressive Symptoms in Pulmonary Tuberculosis Patients With and Without Tracheobronchial Tuberculosis. Front. Psychiatry 9:308. doi: 10.3389/fpsyt.2018.00308
Background and Objective: Anxiety/depression and tuberculosis are global public health problems. The incidence of psychiatric morbidities is high among tuberculosis patients. However, little is known about the prevalence of anxiety and depression among Chinese pulmonary tuberculosis (PTB) patients, especially those with tracheobronchial tuberculosis (TBTB). The goal of the present study was to explore the prevalence of and associated factors of anxiety and depressive symptoms among PTB patients with and without TBTB.

Methods: A cross-sectional survey of PTB patients from three hospitals in Liaoning, China, was conducted using a structured questionnaire. Depression and anxiety were evaluated by using the Hospital Anxiety and Depression Scale (HADS) and the Patient Health Questionnaire-9 (PHQ-9).

Results: According to HADS and PHQ-9, 17.73 and 18.13\% of 1252 PTB patients, respectively, had significant depressive symptoms and based on HADS scale, 18.37\% had significant anxiety symptoms. Approximately $70 \%$ of patients with probable depression also had significant anxiety symptoms, and vice versa, and 69.6\% patients with anxiety symptoms were also diagnosed with probable depression in our study population. Dyspnea and TBTB were significantly associated with depressive symptoms. Other depressive symptoms-related factors included age, divorce, abnormal body mass index (BMI), and low income. Patients with lower incomes, symptoms of dyspnea, or a combination of $\geq 3$ clinical symptoms had an increased risk of anxiety symptoms, while patients with occasional or frequent alcohol consumption had a reduced risk of anxiety symptoms.

Conclusion: Depressive and anxiety symptoms are common among PTB patients, especially those with TBTB. Screening for depression and anxiety is essential for identifying patients who require further psychosocial assessment and support.

Keywords: tuberculosis, social support, mental health, depression, anxiety, tracheobronchial tuberculosis 


\section{INTRODUCTION}

Tuberculosis (TB) remains one of the world's deadliest communicable diseases. In 2014, 9.6 million people (5.4 million men, 3.2 million women, and 1.0 million children) developed $\mathrm{TB}$, and 1.5 million (890,000 men, 480,000 women and 140,000 children) died from TB. China has both a high TB burden and a high multidrug-resistant TB burden ${ }^{1}$. Patients with TB may suffer from mental disorders as a result of long-term treatment, anti-TB drug side effects and TB relapses $(1,2)$. Anxiety and depression are common mental disorders and global public health concerns. The World Health Organization (WHO) estimates that more than 350 million people suffer from depression and that almost 1.0 million people take their own lives each year ${ }^{2}$. However, most people with mental health problems who live in low- or middle-income countries are undiagnosed or improperly treated $(1,3)$. It is well known that the prevalence of depression is high among people with chronic diseases (4-8), and several studies have reported that psychiatric morbidities are common in TB patients $(1,2,9$, 10). Depression is associated with poor treatment adherence in patients with chronic diseases. Poor treatment adherence may lead to irregular treatment and lower treatment success rates (6). Previous studies reported that the prevalence of depression in patients with pulmonary tuberculosis (ranging from 13.5 to $72 \%)$ was higher than that in the general population $(2,11-$ 15). However, little is known about the prevalence of anxiety and depression among TB patients in China, and little is known about whether tracheobronchial tuberculosis (TBTB) influences symptoms of anxiety or depression. Studies also suggested that the identification rate of depression was underestimated in a general hospital in China (16). The present study aimed to evaluate the prevalence of and factors associated with depressive and anxiety symptoms among TB patients with and without TBTB in Liaoning Province, China and to evaluate whether TBTB is a risk factor for depressive symptoms and/or anxiety symptoms.

\section{METHODS}

\section{Study Design}

A cross-sectional survey was conducted to describe anxiety and depression states and the social factors among pulmonary tuberculosis (PTB) patients with and without TBTB.

\section{Study Site}

This study was conducted in three hospitals in Liaoning Province, China, that care for patients with TB.

Abbreviations: PTB, pulmonary tuberculosis; TBTB, tracheobronchial tuberculosis; HADS, Hospital Anxiety and Depression Scale; PHQ-9, Patient Health Questionnaire-9; TB, tuberculosis; DOT, directly observed therapy; mMRC dyspnea scale, modified Medical Research Council dyspnea scale; ORs, odds ratios; 95\% CIs, 95\% confidence intervals; BMI, body mass index; DM, diabetes mellitus; COPD, chronic obstructive pulmonary disease.

${ }^{1}$ http://apps.who.int/iris/bitstream/10665/191102/1/9789241565059eng.pdf.

${ }^{2} \mathrm{http}: / /$ www.who.int/mediacentre/factsheets/fs369/en/.

\section{Subjects}

We recruited PTB patients who were inpatients and newly diagnosed or were undergoing treatment via directly observed therapy (DOT) between May 2014 and October 2015 for this study. All patients underwent bronchoscopy. Patients with drug resistance; patients with simple extra-pulmonary $\mathrm{TB}$ without PTB; patients aged $<18$ years; patients who were pregnant, were critically ill, or had communication problems; and patients with severe illnesses, such as cancer, were excluded from this study. We finally enrolled 1252 patients in the study. All cases of PTB were diagnosed according to microbiological testing, and all diagnoses of tracheobronchial tuberculosis were confirmed via bronchoscopy. The diagnosis of TBTB was confirmed via bronchoscopy and histology, as well as microbiological testing (tissue biopsy and/or brushing sample cultures for MTB) (17). We divided patients with TBTB into 7 subtypes based on bronchoscopic manifestations: caseating, edematous-hyperemic, fibrostenotic, granular, tumorous, ulcerative, and non-specific bronchitis (17). Additionally, airway stenosis was classified into five grades according to the decrease in the cross-sectional area of the airway: grade $1(<25 \%)$, grade $2(25-50 \%)$, grade $3(50-75 \%)$, grade 4 (75-90\%), and grade 5 (90-100\%) (18).

\section{Data Collection}

Consecutive PTB patients admitted to three hospitals who met our inclusion criteria were enrolled in this study. Data were collected using a structured questionnaire administered by data collectors. These data collectors were doctors practicing at the abovementioned hospitals and were provided uniform training to conduct standardized interviews and collect data. The structured questionnaire was designed to collect information regarding socio-demographic factors, such as demographics, body mass index (BMI), educational level, occupation status, marital status, monthly income, family history, smoking status, alcohol consumption, comorbidities, TB symptoms, and other social factors. The Hospital Anxiety and Depression Scale (HADS) and the Patient Health Questionnaire-9 (PHQ-9) were included in the questionnaire to evaluate patient depressive and anxiety symptoms. The modified Medical Research Council (mMRC) Dyspnea Scale was used to evaluate dyspnea severity. All the scales were the Chinese versions, which were valid and efficient tools for screening for depression and anxiety (19-21). Patient information pertaining to treatment was collected from the medical databases of the health facilities to which the patients were admitted.

\section{HADS}

HADS is a questionnaire comprising 14 items that is used to screen for symptoms of anxiety and depression. Subscales comprising seven items were used to evaluate both anxiety and depression. Scores of 8 or above on the anxiety or depression subscale were considered indicative of probable "caseness" for either disorder (22).

\section{PHQ-9}

Depression was assessed using the nine-item PHQ-9, a selfadministered version of the PRIME-MD diagnostic instrument 
for common mental disorders. The PHQ-9 consists of 9 questions based on the DSM-IV diagnostic criteria for depressive disorders. Each of these nine items can be scored as 0 (not at all), 1 (several days), 2 (more than half of the days), or 3 (nearly every day). The total score on the questionnaire ranges from 0 to 27 . PHQ-9 scores can be dichotomized using a cut-off score of 10, which has a high sensitivity and specificity for the diagnosis of depression $(23,24)$. The PHQ-9 tool has been demonstrated to be widely useful for assessing patients, including TB patients, for depressive symptoms (25-27). Thus, PHQ-9 scores of 10 or above are considered indicative of probable "caseness" for depression.

\section{mMRC Dyspnea Scale}

We assessed dyspnea severity using the mMRC dyspnea scale, which consists of five dyspnea severity grades ranging from none (grade 0) to almost complete incapacity (grade 4): Grade 0 (I only get breathless with strenuous exercise); Grade 1 (I get short of breath when hurrying on the level or walking up a slight hill); Grade 2 (I walk slower than people of the same age on the level because of breathlessness, or I have to stop for breath when walking on my own pace on the level); Grade 3 (I stop for breath after walking $\sim 100$ meters or after a few minutes on the level); Grade 4 (I am too breathless to leave the house or I am breathless when dressing or undressing) (28).

\section{Statistical Analysis}

Normally distributed data are reported as the means \pm standard deviation, and comparisons between groups were conducted using Student's $t$ test or the Mann-Whitney U test as appropriate. $\chi^{2}$-tests were used to compare proportions between groups. Odds ratios (ORs) pertaining to the relationships between risk factors and outcomes (anxiety or depression) along with their corresponding 95\% confidence intervals (95\% CIs) were calculated. Variables that were considered risk factors for anxiety and depression $(p<0.1)$ were entered into a multivariate logistic regression model to calculate the ORs and their confidence intervals. $P$-values $<0.05$ were considered significant. All statistical analyses were performed using Statistical Package for Social Sciences (SPSS) version 17.0 for Windows (SPSS Institute Inc., Chicago, Illinois, USA).

\section{Ethical Considerations}

Ethical approval was obtained from the Institutional Ethical Review Board of the First Hospital of China Medical University, Shenyang, China. In addition, research permission was obtained from each hospital. All patients provided written informed consent to participate in this study. We suggested that the patients with depressive and anxiety symptoms undergo further evaluation at the department of mental disease.

\section{RESULTS}

\section{Socioeconomic and Demographic Characteristics}

Of the PTB patients enrolled in this study, 739 (59.03\%) were male, and 513 (40.97\%) were female. The mean age at diagnosis was 44.35 years. Approximately $57.91 \%$ of patients exhibited more than 4 symptoms, and 217 (17.33\%) patients had TBTB. A total of $212(16.93 \%)$ patients had a low BMI $<18.5 \mathrm{~kg} / \mathrm{m}^{2}$ and $79(6.31 \%)$ patients had a high BMI $\left(>25 \mathrm{~kg} / \mathrm{m}^{2}\right)$. All the patient characteristics are shown in Table 1.

\section{Prevalence of Depressive and Anxiety Symptoms Among TB Patients}

A total of $222(17.73 \%)$ PTB patients were found to have depressive symptoms according to the PHQ-9, and 227 (18.13\%) PTB patients were found to have depressive symptoms according to the HADS. The prevalence of probable depression, as determined by the above scales, was similar $(p>0.05)$. A total of $230(18.37 \%)$ PTB patients were found to have anxiety symptoms according to HADS. A total of 160 (12.78\%) PTB patients had both depressive and anxiety symptoms and had a high mMRC dyspnea score compared to those with depressive symptoms or anxiety symptoms only (Table 2 ).

\section{Factors Associated With Depressive Symptoms According to the Different Diagnostic Scales}

According to a multivariate analysis, a PHQ-9 score $>10$ was associated with older age, divorce, abnormal BMI, dyspnea, and TBTB. Protective factors (according to a multivariate analysis) included normal BMI (18.5 $\leq$ BMI $<25)$, monthly income $\geq 1,500$ Yuan (RMB), higher education level (vocational/college/undergraduate) and employment (Table 3).

When depressive symptoms were assessed using the HADS$\mathrm{D}$, only dyspnea and TBTB remained as risk factors, as well as a monthly income $<1,500$ Yuan (RMB). Common protective factors (according to a multivariate analysis) included monthly income $\geq 1,500$ Yuan (RMB) (Table 3).

The potential risk factors for anxiety symptoms were examined using multivariate models. Patients suffering from high-grade dyspnea, as determined using the mMRC dyspnea scale, were at increased risk for anxiety symptoms. Moreover, normal BMI and employment were protective factors against anxiety symptoms among PTB patients. The results of this analysis are presented in Table 3.

\section{Comparative Analysis of TB Patients With and Without TBTB}

Two depression screening scales (HADS and PHQ-9) demonstrated that TB patients with TBTB were more likely to suffer from probable depression than were $\mathrm{TB}$ patients without TBTB. The ORs pertaining to the risk of depressive symptoms in these groups of patients were 1.451 and 1.656, respectively. Moreover, TBTB was significantly related to anxiety symptoms, according to the HADS (Table 4).

\section{The Impact of Different Characteristics of TBTB on the Prevalence of Depressive and Anxiety Symptoms}

We grouped TBTB patients according to the different characteristics and compared the incidence of depressive and anxiety symptoms evaluated by the PHQ9 and HADS (Table 5). 
TABLE 1 | Characteristics of PTB patients.

\begin{tabular}{|c|c|c|c|}
\hline Characteristic & Mean $\pm S D$ & $n$ & (\%) \\
\hline Age, years & $44.35 \pm 17.36$ & & \\
\hline $18-30$ & & 380 & 30.35 \\
\hline $31-50$ & & 371 & 29.63 \\
\hline $51-80$ & & 466 & 37.22 \\
\hline$>80$ & & 35 & 2.80 \\
\hline \multicolumn{4}{|l|}{ SEX } \\
\hline Male & & 739 & 59.03 \\
\hline Female & & 513 & 40.97 \\
\hline BMI, $\mathrm{kg} / \mathrm{m}^{2}$ & $21.37 \pm 3.48$ & & \\
\hline$<18.5$ & & 212 & 16.93 \\
\hline $18.5-25$ & & 958 & 76.52 \\
\hline$>25$ & & 79 & 6.31 \\
\hline \multicolumn{4}{|c|}{ MONTHLY INCOME, YUAN } \\
\hline$<1,500$ & & 319 & 25.48 \\
\hline $1,500-3,000$ & & 555 & 44.33 \\
\hline $3,000-5,000$ & & 279 & 22.28 \\
\hline $5,000-1,000$ & & 47 & 3.75 \\
\hline$>10,000$ & & 13 & 1.04 \\
\hline \multicolumn{4}{|l|}{ MARITAL STATUS } \\
\hline Single & & 347 & 27.72 \\
\hline Married & & 845 & 67.49 \\
\hline Divorced & & 40 & 3.19 \\
\hline Widowed & & 19 & 1.52 \\
\hline \multicolumn{4}{|c|}{ EDUCATION LEVEL } \\
\hline Elementary & & 121 & 9.66 \\
\hline Middle school & & 429 & 34.27 \\
\hline High school & & 341 & 27.24 \\
\hline Vocational/college & & 332 & 26.52 \\
\hline Undergraduate & & 16 & 1.28 \\
\hline None & & 12 & 0.96 \\
\hline \multicolumn{4}{|c|}{ ALCOHOL CONSUMPTION } \\
\hline Never drinker & & 711 & 56.79 \\
\hline Occasional drinker & & 367 & 29.31 \\
\hline Frequent drinker & & 174 & 13.90 \\
\hline \multicolumn{4}{|l|}{ SMOKING } \\
\hline Never smoker & & 830 & 66.29 \\
\hline Current smoker & & 283 & 22.60 \\
\hline Former smoker & & 139 & 11.10 \\
\hline \multicolumn{4}{|l|}{ MD FAMILY } \\
\hline No & & 1,248 & 99.68 \\
\hline Yes & & 4 & 0.32 \\
\hline \multicolumn{4}{|l|}{ TB FAMILY } \\
\hline No & & 1,191 & 95.13 \\
\hline Yes & & 61 & 4.87 \\
\hline \multicolumn{4}{|l|}{ DUST EXPOSURE } \\
\hline No & & 1,166 & 93.13 \\
\hline Yes & & 64 & 5.11 \\
\hline \multicolumn{4}{|c|}{ OCCUPATION STATUS } \\
\hline Unemployed & & 728 & 57.41 \\
\hline Employed & & 534 & 42.11 \\
\hline
\end{tabular}

(Continued)
TABLE 1 | Continued

\begin{tabular}{|c|c|c|c|}
\hline Characteristic & Mean $\pm S D$ & $n$ & $(\%)$ \\
\hline \multicolumn{4}{|c|}{ mMRC DYSPNEA SCORE } \\
\hline 0 & & 699 & 55.83 \\
\hline 1 & & 356 & 28.43 \\
\hline 2 & & 125 & 9.98 \\
\hline 3 & & 49 & 3.91 \\
\hline 4 & & 23 & 1.84 \\
\hline \multicolumn{4}{|l|}{ SYMPTOMS $\geq 4$} \\
\hline No & & 527 & 42.09 \\
\hline Yes & & 725 & 57.91 \\
\hline \multicolumn{4}{|l|}{ COPD } \\
\hline No & & 1,224 & 97.76 \\
\hline Yes & & 28 & 2.24 \\
\hline \multicolumn{4}{|c|}{ TRACHEOBRONCHIAL TUBERCULOSIS } \\
\hline No & & 1,035 & 82.67 \\
\hline Yes & & 217 & 17.33 \\
\hline
\end{tabular}

PTB, pulmonary tuberculosis; BMI, body mass index; $M D$, mental disorder; $T B$, tuberculosis; $m M R C$, modified Medical Research Council.

No difference was found when comparing the incidence of depressive and anxiety symptoms in patients with different of bronchoscopic subtypes $(p>0.05)$. Additionally, a comparison of TBTB patients with tracheal/bronchial involvement with those without central airway involvement showed that the incidence of depressive and anxiety symptoms was not significantly different between the two groups $(p>0.05)$. Our results revealed that, among TBTB patients, those with grade 4 stenosis had a higher incidence of depressive and anxiety symptoms than those with grade $1-3$ stenosis $(p=0.005 ; 0.005 ; 0.023)$. The patient with grade 5 stenosis was not included because our sample did not contained case with grade 5 stenosis.

\section{The Impact of Interventional Therapy on the Prevalence of Depressive and Anxiety Symptoms Among TBTB Patients With Central Airway Involvement}

Among TBTB patients with central airway involvement, treated patients had a lower incidence of depressive and anxiety symptoms than those in the untreated group $(p=0.001 ; 0.007$; $<0.001$; Table 6). Interventional therapy may be a protective factor against depressive and anxiety symptoms.

\section{DISCUSSION}

In recent years, the psychiatric status of patients with $\mathrm{TB}$ has attracted increasing attention because psychiatric illnesses such as anxiety and depression have been confirmed to be associated with poor treatment outcomes in TB patients (1, 29). Unfortunately, there remains a lack of medical literature regarding the prevalence of depressive and anxiety symptoms among PTB patients in China, especially patients with TBTB. Our study included many PTB patients living in Liaoning Province, 
TABLE 2 | Comparative analysis of TB patients with different depression or anxiety status by HADS.

\begin{tabular}{|c|c|c|c|c|}
\hline Demographic characteristic & $\begin{array}{c}\text { Probable } \\
\text { depression only } \\
\text { by PHQ-9 }\end{array}$ & $\begin{array}{c}\text { Probable } \\
\text { anxiety only } \\
\text { by HADS-A }\end{array}$ & $\begin{array}{c}\text { Probable } \\
\text { depression only } \\
\text { by HADS-D }\end{array}$ & $\begin{array}{c}\text { Probable } \\
\text { depression and } \\
\text { anxiety } \\
\text { by HADS-A+HADS-D }\end{array}$ \\
\hline & $n(\%) \mathrm{N}=222$ & $n(\%) \mathrm{N}=70$ & $n(\%) \mathrm{N}=67$ & $n(\%) \mathrm{N}=160$ \\
\hline \multicolumn{5}{|l|}{ AGE, YEARS } \\
\hline $18-30$ & $54(24.32)$ & $25(35.71)$ & $12(17.91)$ & $41(25.63)$ \\
\hline $31-50$ & $71(31.98)$ & $20(28.57)$ & 23 (34.33) & $49(30.63)$ \\
\hline $51-80$ & 89 (40.09) & 24 (34.29) & $31(46.27)$ & $65(40.63)$ \\
\hline $81-88$ & 8 (3.6) & $1(1.43)$ & $1(1.49)$ & $5(3.13)$ \\
\hline \multicolumn{5}{|l|}{ SEX } \\
\hline Male & $136(61.26)$ & 38 (54.29) & $48(71.64)$ & $95(59.38)$ \\
\hline Female & $86(38.74)$ & $32(45.71)$ & $19(28.36)$ & $65(40.63)$ \\
\hline \multicolumn{5}{|l|}{ BMI, KG/M² } \\
\hline$<18.5$ & $55(24.77)$ & $14(20)$ & $11(16.42)$ & $41(25.63)$ \\
\hline$\geq 18.5,<25$ & $151(68.02)$ & $46(65.71)$ & $52(77.61)$ & $107(66.88)$ \\
\hline$\geq 25$ & $16(7.21)$ & $10(14.29)$ & $4(5.97)$ & $12(7.5)$ \\
\hline \multicolumn{5}{|l|}{ MONTHLY INCOME, YUAN } \\
\hline$<1,500$ & 73 (33.95) & $18(27.27)$ & $24(36.92)$ & $55(35.26)$ \\
\hline$\geq 1,500$ & $142(66.05)$ & 48 (72.73) & $41(63.08)$ & $101(64.74)$ \\
\hline \multicolumn{5}{|l|}{ mMRC DYSPNEA SCORE* } \\
\hline 0 & $51(22.97)$ & 25 (35.71) & $29(43.28)$ & $38(23.75)$ \\
\hline 1 & $59(26.58)$ & $25(35.71)$ & $21(31.34)$ & $37(23.13)$ \\
\hline 2 & $60(27.03)$ & $19(27.14)$ & $12(17.91)$ & $37(23.13)$ \\
\hline 3 & $32(14.41)$ & $1(1.43)$ & $4(5.97)$ & $34(21.25)$ \\
\hline 4 & $20(9.01)$ & $0(0)$ & $1(1.49)$ & $14(8.75)$ \\
\hline \multicolumn{5}{|c|}{ TRACHEOBRONCHIAL TUBERCULOSIS } \\
\hline No & $169(76.13)$ & $52(74.29)$ & $52(77.61)$ & $125(78.13)$ \\
\hline Yes & $53(23.87)$ & $18(25.71)$ & 15 (22.39) & $35(21.88)$ \\
\hline
\end{tabular}

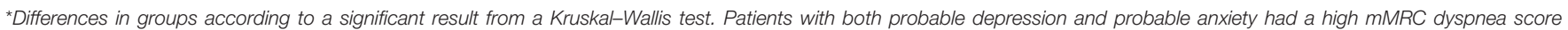
compared to those with probable depression or probable anxiety only.

China. We and our colleagues prospectively administered structured questionnaires to 1252 patients with PTB to evaluate the prevalence of depressive and anxiety symptoms among PTB patients.

The prevalence of probable depression in this PTB population was $17.73 \%$ according to the PHQ-9 and $18.13 \%$ according to the HADS. Other studies determined that the prevalence of depression among patients with TB ranged from $16.8 \%$ in the Philippines to $80 \%$ among hospitalized patients in Pakistan $(30,31)$. Compared with the prevalence of depression noted among patients enrolled in previous studies, the prevalence of probable depression noted among the PTB patients enrolled in the present study was relatively low. One possible explanation for this result is that only the prevalence of major depression was assessed in the present study, whereas other mental disorders were assessed in some previous studies. The abovementioned difference may also have resulted from differences in the races, countries and patient populations evaluated in this study compared with those evaluated in previous studies (the prevalence of depression was highest in hospitalized patients). Our study also noted a non-significant difference in the prevalence of depressive symptoms determined using the PHQ-9 and HADS and determined that the risk factors for depressive symptoms were different when probable depression was diagnosed using different scales.

In this study, we determined that young age (18-30 years) and divorced marital status may increase the risk of probable depression in $\mathrm{TB}$ patients. The increased risk of depressive symptoms noted among young people may be attributable to social pressures and feelings of shame spurred by diagnosis with TB. Patients who are divorced tend to be lonely and have less social support than patients who are married, thus, marital status may be related to depressive symptoms $(9,32)$. However, age had no independent effect when we used the HADS scale. We also determined that dyspnea and large numbers of clinical symptoms $(\geq 4)$ were associated with depressive symptoms among PTB patients. Previous studies demonstrated that multiple symptoms and dyspnea are risk factors for depression not only among PTB patients (31) but also among patients with chronic respiratory diseases, such as COPD and asthma $(11,33)$.Regarding monthly income, PTB patients with high income levels were less likely to suffer from depressive and 
TABLE 3 | Multivariate analysis for probable depression or anxiety among PTB patients.

\begin{tabular}{|c|c|c|c|c|c|c|}
\hline \multirow{2}{*}{$\begin{array}{l}\text { Demographic } \\
\text { characteristic }\end{array}$} & \multicolumn{2}{|c|}{ PHQ-9(P\& aOR[95\%Cl]) } & \multicolumn{2}{|c|}{ HADS-D (P\& aOR[95\%CI]) } & \multicolumn{2}{|c|}{ HADS-A(P\& aOR[95\%Cl]) } \\
\hline & & & & & & \\
\hline $31-50$ & 0.048 & $0.55(0.304,0.994)$ & 0.734 & $0.907(0.515,1.596)$ & 0.219 & $0.702(0.399,1.234)$ \\
\hline $51-80$ & 0.023 & $0.48(0.256,0.902)$ & 0.736 & $0.901(0.49,1.657)$ & 0.340 & $0.746(0.408,1.363)$ \\
\hline Male & & 1.000 & & 1.000 & & 1.000 \\
\hline Female & 0.865 & $0.964(0.63,1.475)$ & 0.522 & $0.877(0.587,1.311)$ & 0.759 & $1.064(0.716,1.58)$ \\
\hline \multicolumn{7}{|l|}{ BMI, KG/M"2 } \\
\hline$<18.5$ & & 1.000 & & 1.000 & & 1.000 \\
\hline$\geq 18.5,<25$ & 0.010 & $0.561(0.362,0.871)$ & 0.147 & $0.73(0.478,1.116)$ & 0.049 & $0.66(0.436,0.999)$ \\
\hline$\geq \ngtr 1,500$ yuan & 0.061 & $0.683(0.459,1.018)$ & 0.007 & $0.602(0.416,0.871)$ & 0.427 & $0.86(0.593,1.247)$ \\
\hline \multicolumn{7}{|l|}{ MARITAL STATUS } \\
\hline Single & & 1.000 & & 1.000 & & 1.000 \\
\hline Married & 0.069 & $1.692(0.96,2.983)$ & 0.928 & $0.975(0.571,1.668)$ & 0.962 & $0.987(0.58,1.679)$ \\
\hline Divorced & 0.007 & $4.018(1.47,10.983)$ & 0.461 & $1.436(0.549,3.757)$ & 0.008 & $3.425(1.375,8.532)$ \\
\hline Widowed & 0.703 & $1.343(0.296,6.088)$ & 0.638 & $0.698(0.156,3.124)$ & 0.872 & $0.882(0.192,4.064)$ \\
\hline \multicolumn{7}{|l|}{ EDUCATION LEVEL } \\
\hline $\begin{array}{l}\text { None/Elementary } \\
\text { school }\end{array}$ & & 1.000 & & 1.000 & & 1.000 \\
\hline Middle /High school & 0.969 & $1.011(0.569,1.798)$ & 0.869 & $0.956(0.561,1.63)$ & 0.891 & $1.039(0.598,1.807)$ \\
\hline $\begin{array}{l}\text { Vocational/college/ } \\
\text { Undergraduate }\end{array}$ & 0.233 & $0.642(0.31,1.33)$ & 0.095 & $0.557(0.281,1.106)$ & 0.776 & $0.905(0.456,1.796)$ \\
\hline
\end{tabular}

\section{ALCOHOL DRINKING}

Never drinker

Occasional drinker

Frequent drinker

\section{SMOKING}

Never smoker

1.000

Current smoker

Former smoker

MD FAMILY

No

Yes

\section{TB FAMILY}

No

Yes

DM

No

Yes

HBP

No

Yes

\section{COPD}

No

1.000

0.382

$0.639(0.234,1.743)$

Yes
1.000

$1.222(0.584,2.553)$

1.000

0.072

$1.535(0.962,2.449)$
0.102

0.473
1.000
$1.434(0.931,2.209)$

$1.221(0.707,2.11)$
1.000

$1.229(0.789,1.913)$

$1.348(0.775,2.342)$
1.000

0.759

$1.12(0.542,2.316)$

1.000

$13(0.722,1.768)$
1.000

$1.11(0.438,2.812)$

0.826
0.362

0.290
1.000

1.055 (0.522, 2.129) 
TABLE 3 | Continued

\begin{tabular}{|c|c|c|c|c|c|c|}
\hline Demographic & \multicolumn{2}{|c|}{ PHQ-9(P\& aOR[95\%Cl]) } & \multicolumn{2}{|c|}{ HADS-D (P\& aOR[95\%Cl]) } & \multicolumn{2}{|c|}{ HADS-A(P\& aOR $[95 \% \mathrm{Cl}])$} \\
\hline \multicolumn{7}{|c|}{ DUST EXPOSURE } \\
\hline No & & 1.000 & & 1.000 & & \\
\hline Yes & 0.108 & $1.779(0.882,3.591)$ & 0.408 & $1.338(0.672,2.663)$ & & \\
\hline \multicolumn{7}{|c|}{ OCCUPATION STATUS } \\
\hline Unemployed & & 1.000 & & 1.000 & & 1.000 \\
\hline Employed & 0.970 & $0.993(0.674,1.463)$ & 0.810 & $0.956(0.662,1.381)$ & 0.008 & $0.606(0.418,0.878)$ \\
\hline \multicolumn{7}{|l|}{ mMRC SCORE } \\
\hline 0 & & & & & & 1.000 \\
\hline 1 & 0.000 & $2.332(1.525,3.568)$ & 0.011 & $1.662(1.121,2.463)$ & 0.002 & $1.904(1.279,2.835)$ \\
\hline 2 & 0.000 & $12.512(7.497,20.879)$ & 0.000 & $5.537(3.407,8.998)$ & 0.000 & $7.526(4.639,12.211)$ \\
\hline 3 & 0.000 & $\begin{array}{c}28.781(14.104 \\
58.732)\end{array}$ & 0.000 & $\begin{array}{c}31.527(14.862 \\
66.882)\end{array}$ & 0.000 & $\begin{array}{c}30.952(14.974 \\
63.977)\end{array}$ \\
\hline 4 & 0.000 & $\begin{array}{c}87.322(21.822 \\
349.425)\end{array}$ & 0.000 & $14.37(5.221,39.548)$ & 0.000 & $14.718(5.407,40.064)$ \\
\hline \multicolumn{7}{|l|}{ SYMPTOMS $\geq 4$} \\
\hline No & & 1.000 & & 1.000 & & 1.000 \\
\hline Yes & 0.567 & $0.895(0.612,1.309)$ & 0.502 & $0.886(0.622,1.262)$ & 0.608 & $1.099(0.767,1.575)$ \\
\hline \multicolumn{7}{|c|}{ TRACHEOBRONCHIAL TUBERCULOSIS } \\
\hline No & & 1.000 & & 1.000 & & 1.000 \\
\hline Yes & 0.008 & $1.944(1.188,3.18)$ & 0.004 & $1.991(1.25,3.171)$ & 0.025 & $1.68(1.067,2.645)$ \\
\hline
\end{tabular}

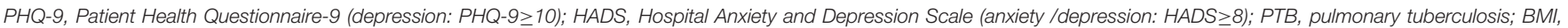

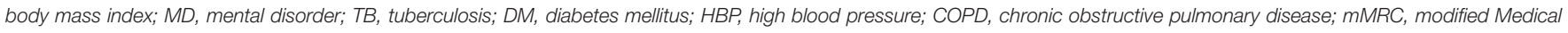
Research Council.

TABLE 4 | Comparative analysis of TB patients with or without TBTB.

\begin{tabular}{|c|c|c|c|c|c|c|c|c|}
\hline & \multicolumn{2}{|c|}{ With ТВTВ $(n=217)$} & \multicolumn{2}{|c|}{ Without TBTB $(n=1,035)$} & \multirow[b]{2}{*}{$p$} & \multirow[b]{2}{*}{ OR } & & \\
\hline & $\mathbf{N}$ & $\%$ & $\mathbf{N}$ & $\%$ & & & \multicolumn{2}{|c|}{$95 \% \mathrm{Cl}$} \\
\hline $\begin{array}{l}\text { Anxiety } \\
\text { symptoms } \\
\text { (HADS) }\end{array}$ & 53 & 24.42 & 177 & 17.10 & 0.011 & 1.567 & 1.105 & 2.222 \\
\hline $\begin{array}{l}\text { Depression } \\
\text { Symptoms(HADS) }\end{array}$ & 50 & 23.04 & 177 & 17.10 & 0.039 & 1.451 & 1.018 & 2.070 \\
\hline $\begin{array}{l}\text { Depressive } \\
\text { symptoms(PHQ-9) }\end{array}$ & 21 & 9.68 & 50 & 4.83 & 0.005 & 2.111 & 1.240 & 3.594 \\
\hline \multicolumn{9}{|c|}{ mMRC DYSPNEA SCORE } \\
\hline 0 & 114 & 52.53 & 585 & 56.52 & - & & & \\
\hline 1 & 65 & 29.95 & 291 & 28.12 & 0.425 & 1.146 & 0.820 & 1.603 \\
\hline 2 & 26 & 11.98 & 99 & 9.57 & 0.219 & 1.348 & 0.837 & 2.170 \\
\hline 3 & 7 & 3.23 & 42 & 4.06 & 0.710 & 0.855 & 0.375 & 1.951 \\
\hline 4 & 5 & 2.30 & 18 & 1.74 & 0.492 & 1.425 & 0.519 & 3.917 \\
\hline
\end{tabular}

anxiety symptoms than were patients with low income levels $(9,15,34)$. This study also demonstrated that smoking history was correlated with depressive symptoms among PTB patients. Smoking is also a risk factor for depression in the general population $(1,35)$.

Interestingly, alcohol consumption, whether occasional or frequent, was associated with a reduced risk of anxiety symptoms. In our study, patients usually did not meet the criteria for the diagnosis of alcohol abuse. Perhaps the negative coping of these patients through alcohol consumption served to ameliorate anxiety in the short term. A study focusing on the longitudinal associations between different levels of alcohol consumption and new-onset depression and generalized anxiety disorder demonstrated that light-to-moderate alcohol consumption was a protective factor against depression and generalized anxiety. The authors of that study attributed their findings to the 
TABLE 5 | Comparative analysis of TB patients with different characteristics of TBTB.

\begin{tabular}{|c|c|c|c|c|c|c|c|}
\hline & & PHQ9 & & HADS-A & & HADS_D & \\
\hline & & $n(\%)$ & $\chi 2 / p$ & $n(\%)$ & $\times 2 / p$ & $n(\%)$ & $\chi 2 / p$ \\
\hline \multirow[t]{7}{*}{$\begin{array}{l}\text { Bronchoscopic } \\
\text { subtype }\end{array}$} & Fibrostenotic & $\begin{array}{c}15 / 58 \\
(25.86)\end{array}$ & $\begin{array}{l}5.891 / \\
0.317\end{array}$ & $\begin{array}{c}13 / 58 \\
(22.41)\end{array}$ & $\begin{array}{l}5.061 / \\
0.408\end{array}$ & 15/58 (25.86) & $\begin{array}{l}6.075 / \\
0.299\end{array}$ \\
\hline & $\begin{array}{l}\text { Edematous- } \\
\text { hyperemic }\end{array}$ & $\begin{array}{c}16 / 70 \\
(22.86)\end{array}$ & & $\begin{array}{l}17 / 70 \\
(24.29)\end{array}$ & & $17 / 70(24.29)$ & \\
\hline & Granular & $0 / 11(0)$ & & $\begin{array}{l}1 / 11 \\
(9.09)\end{array}$ & & 1/11 (9.09) & \\
\hline & Tumorous & $2 / 5(40)$ & & $3 / 5(60)$ & & $3 / 5(60)$ & \\
\hline & Caseating & $\begin{array}{c}18 / 69 \\
(26.09)\end{array}$ & & $\begin{array}{l}18 / 69 \\
(26.09)\end{array}$ & & 13/69 (18.84) & \\
\hline & Ulcerative & 2/4 (50) & & $1 / 4(25)$ & & $1 / 4(25)$ & \\
\hline & Total & $\begin{array}{l}53 / 217 \\
(24.42)\end{array}$ & & $\begin{array}{l}53 / 217 \\
(24.42)\end{array}$ & & $\begin{array}{l}50 / 217 \\
(23.04)\end{array}$ & \\
\hline \multirow[t]{3}{*}{$\begin{array}{l}\text { Involved } \\
\text { site }\end{array}$} & $\begin{array}{l}\text { Non-trachea/main } \\
\text { bronchus }\end{array}$ & $\begin{array}{c}32 / 141 \\
(22.7)\end{array}$ & $\begin{array}{l}0.652 / \\
0.419\end{array}$ & $\begin{array}{c}33 / 141 \\
(23.4)\end{array}$ & $\begin{array}{l}0.227 / \\
0.634\end{array}$ & $33 / 141$ (23.4) & $\begin{array}{l}0.030 / \\
0.863\end{array}$ \\
\hline & $\begin{array}{l}\text { Trachea/main } \\
\text { bronchus }\end{array}$ & $\begin{array}{l}21 / 76 \\
(27.63)\end{array}$ & & $\begin{array}{l}20 / 76 \\
(26.32)\end{array}$ & & $17 / 76(22.37)$ & \\
\hline & Total & $\begin{array}{l}53 / 217 \\
(24.42)\end{array}$ & & $\begin{array}{l}53 / 217 \\
(24.42)\end{array}$ & & $\begin{array}{l}50 / 217 \\
(23.04)\end{array}$ & \\
\hline \multirow[t]{5}{*}{$\begin{array}{l}\text { Stenosis } \\
\text { grading }\end{array}$} & 1 & $\begin{array}{c}14 / 57 \\
(24.56)\end{array}$ & $\begin{array}{l}8.691 / \\
0.034 \\
7.913 / \\
0.005^{\star}\end{array}$ & $\begin{array}{l}17 / 57 \\
(29.82)\end{array}$ & $\begin{array}{l}16.09 / \\
0.001 \\
7.913 / \\
0.005^{\star}\end{array}$ & 19/57 (33.33) & $\begin{array}{c}14.675 / \\
0.002 \\
5.206 / \\
0.023^{\star}\end{array}$ \\
\hline & 2 & $\begin{array}{c}14 / 74 \\
(18.92)\end{array}$ & & $\begin{array}{c}9 / 74 \\
(12.16)\end{array}$ & & $7 / 74(9.46)$ & \\
\hline & 3 & $\begin{array}{c}18 / 74 \\
(24.32)\end{array}$ & & $\begin{array}{l}20 / 74 \\
(27.03)\end{array}$ & & 18/74 (24.32) & \\
\hline & 4 & $\begin{array}{c}7 / 12 \\
(58.33)\end{array}$ & & $\begin{array}{c}7 / 12 \\
(58.33)\end{array}$ & & $6 / 12(50)$ & \\
\hline & Total & $\begin{array}{l}53 / 217 \\
(24.42)\end{array}$ & & $\begin{array}{l}53 / 217 \\
(24.42)\end{array}$ & & $\begin{array}{l}50 / 217 \\
(23.04)\end{array}$ & \\
\hline
\end{tabular}

${ }^{*}$ Comparison of Grade 4 cases with the combined set of Grade 1-3 cases.

TABLE 6 | The impact of Interventional therapy on prevalence of depression and anxiety symptoms among TBTB patients with central airway involvement.

\begin{tabular}{lcccc}
\hline & $\begin{array}{c}\text { Untreated } \\
\text { group } \\
\boldsymbol{n}(\%)\end{array}$ & $\begin{array}{c}\text { Treated } \\
\text { group } \\
\boldsymbol{n}(\%)\end{array}$ & $p$ & OR (95\%Cl) \\
\hline $\begin{array}{l}\text { Anxiety } \\
\text { Symptoms(HADS) } \\
\text { Depression }\end{array}$ & $15 / 32(46.88)$ & $5 / 44(11.36)$ & 0.001 & $0.145(0.045,0.464)$ \\
$\begin{array}{l}\text { Symptoms(HADS) } \\
\text { Depression } \\
\text { Symptoms(PHQ-9) }\end{array}$ & $12 / 32(37.5)$ & $5 / 44(11.36)$ & 0.007 & $0.214(0.066,0.691)$ \\
\hline
\end{tabular}

antidepressant and anxiolytic effects of moderate alcohol use. However, the exact mechanism underlying the effects of alcohol on depression is largely unknown (36).

Finally, our PHQ-9 and HADS results indicated that PTB patients with TBTB were more likely to suffer from probable depression than PTB patients without TBTB. This is the first report to focus on the effects of TBTB on the prevalence of probable depression among PTB patients. A previous study noted that 15 to $90 \%$ of patients with TBTB have some degree of bronchial stenosis $(37,38)$. Thus, the high prevalence of probable depression noted among TBTB patients may be associated with the dyspnea caused by bronchial stenosis. Our finding that patients with the higher severity of stenosis (grade 4 stenosis) had the highest incidence of depressive and anxiety symptoms among TBTB patients supports this hypothesis. On the other hand, the high prevalence of probable depression noted among TBTB patients may be associated with some consistent symptoms such as non-productive cough, which is more common in patients with TBTB than patients with PTB. However, in our study, neither the site of airway involvement nor the bronchoscopic subtypes of TBTB were associated with significant differences in the incidence of depressive and anxiety symptoms. Further research including a larger sample size should be performed to better understand the association between TBTB and depression.

In addition, interventional pulmonology treatments for TBTB may be associated with mental health. We found that treated 
patients had a lower incidence of anxiety and depressive symptoms than the untreated group among TBTB patients with central airway involvement, which may result from the fact that the interventional treatment can relieve the symptoms of dyspnea.

Additional studies regarding the risk factors for depressive symptoms among TBTB patients are necessary. Once the diagnosis of TBTB has been confirmed, clinicians should pay attention to the mental statuses of patients and assess patients for symptoms of anxiety and depression.

Some limitations of this study should be mentioned. First, as this was a cross-sectional study, we cannot exclude the possibility that our results were affected by recall bias such as a family history of mental disorders and tuberculosis which may under-estimate those factors. Furthermore, a comparison of our results to healthy controls was not possible due to the absence of a control group. Because not all the participated hospitals having department of mental disorder and only used screening questionnaires for anxiety and depression, our study only evaluated the prevalence and risk factors of probable anxiety and depression. But our study still offered valuable information for further study in this field. Finally, cross-sectional surveys can demonstrate associations but cannot demonstrate temporal sequences of events, which may raise concerns regarding the directions of causality between risk factors and depression in patients with TB (39).

\section{REFERENCES}

1. Duko B, Gebeyehu A, Ayano G. Prevalence and correlates of depression and anxiety among patients with tuberculosis at WolaitaSodo University Hospital and Sodo Health Center, WolaitaSodo, South Ethiopia, Cross sectional study. BMC Psychiatry (2015) 15:214. doi: 10.1186/s12888-015-0598-3

2. Husain MO, Dearman SP, Chaudhry IB, Rizvi N, Waheed W. The relationship between anxiety, depression and illness perception in tberculosis patients in Pakistan. Clin Pract Epidemiol Mental Health (2008) 4:4. doi: 10.1186/1745-0179-4-4

3. Goncalves DA, Mari Jde J, Bower P, Gask L, Dowrick C, Tofoli LF, et al. Brazilian multicentre study of common mental disorders in primary care: rates and related social and demographic factors. Cadernos Saude Publica (2014) 30:623-32. doi: 10.1590/0102-311X00 158412

4. Boing AF, Melo GR, Boing AC, Moretti-Pires RO, Peres KG, Peres MA. Association between depression and chronic diseases: results from a population-based study. Rev Saude Publica (2012) 46:617-23. doi: 10.1590/S0034-89102012005000044

5. Cassano P, Fava M. Depression and public health: an overview. J Psychosomatic Res. (2002) 53:849-57. doi: 10.1016/S0022-3999(02)00304-5

6. Katon W, Schulberg H. Epidemiology of depression in primary care. Gen Hospital psychiatry (1992) 14:237-47. doi: 10.1016/0163-8343(92)90094-Q

7. Noel PH, Williams JW Jr, Unutzer J, Worchel J, Lee S, Cornell J, et al. Depression and comorbid illness in elderly primary care patients: impact on multiple domains of health status and well-being. Ann Family Med. (2004) 2:555-62. doi: 10.1370/afm.143

8. Katon WJ. Epidemiology and treatment of depression in patients with chronic medical illness. Dialog Clin Neurosci. (2011) 13:7-23. doi: 10.1089/jwh.2010.2662

9. Peltzer K, Naidoo P, Matseke G, Louw J, McHunu G, Tutshana B. Prevalence of psychological distress and associated factors in tuberculosis patients in public primary care clinics in South Africa. BMC Psychiatry (2012) 12:89. doi: $10.1186 / 1471-244 \mathrm{X}-12-89$

\section{CONCLUSION}

Our study determined the prevalence of and factors associated with depressive and anxiety symptoms among PTB patients in Liaoning Province, China. As depressive and anxiety symptoms are common among PTB patients, especially those with TBTB, screening for depression and anxiety can identify patients who require further psychosocial assessment, support and treatment to experience a better clinical response to anti-TB treatment.

\section{AUTHOR CONTRIBUTIONS}

GH: Substantial contributions to the conception or design of the work, Interpretation of data for the work; XW and XL: Analysis of data for the work; GH, XW, and XL: Drafting the work; All the authors: Acquisition of data for the work, Revising the work critically for important intellectual content, Final approval of the version to be published, Agreement to be accountable for all aspects of the work in ensuring that questions related to the accuracy or integrity of any part of the work are appropriately investigated and resolved.

\section{ACKNOWLEDGMENTS}

This research was supported by grant LT2013015 from the Department of Education of Liaoning Province, China.

10. Ige OM, Lasebikan VO. Prevalence of depression in tuberculosis patients in comparison with non-tuberculosis family contacts visiting the DOTS clinic in a Nigerian tertiary care hospital and its correlation with disease pattern. Mental Health Fam Med. (2011) 8:235-41.

11. Moussas G, Tselebis A, Karkanias A, Stamouli D, Ilias I, Bratis D, et al. A comparative study of anxiety and depression in patients with bronchial asthma, chronic obstructive pulmonary disease and tuberculosis in a general hospital of chest diseases. Ann Gen Psychiatry (2008) 7:7. doi: 10.1186/1744-859X-7-7

12. Aamir S, Aisha. Co-morbid anxiety and depression among pulmonary tuberculosis patients. J Coll Phys Surg Pak. (2010) 20:703-4. doi: 10.2010/JCPSP.703704

13. Balaji AL, Abhishekh HA, Kumar NC, Mehta RM. Depression in patients with pulmonary tuberculosis in a tertiary care general hospital. Asian J Psychiatry (2013) 6:251-2. doi: 10.1016/j.ajp.2012.12.017

14. Natani GD, Jain NK, Sharma TN, Gehlot PS, Agrawal SP, Koolwal S, et al. Depression in tuberculosis patients: correlation with duration of disease and response to anti-tuberculous chemotherapy. Ind J Tuberculosis (1985) 32:195-8.

15. Shen TC, Wang CY, Lin CL, Liao WC, Chen CH, Tu CY, et al. People with tuberculosis are associated with a subsequent risk of depression. Eur J Int Med. (2014) 25:936-40. doi: 10.1016/j.ejim.2014.10.006

16. Zheng L, Jun-juan Z, Jun C, Yu-shan L, Shen-xun S, Yi-jue S, et al. A controlled study on identification for depression and effectiveness of its treatment in psychiatric clinics of general hospitals. Chin J Gen Pract. (2008) 7:231-4. doi: 10.3760/cma.j.issn.1671-7368.2008.04.007

17. Chung HS, Lee JH. Bronchoscopic assessment of the evolution of endobronchial tuberculosis. Chest (2000) 117:385-92. doi: 10.1378/chest.117. 2.385

18. Freitag L, Ernst A, Unger M, Kovitz K, Marquette CH. A proposed classification system of central airway stenosis. Eur Resp J. (2007) 30:7-12. doi: 10.1183/09031936.00132804

19. Yang Y, Ding R, Hu D, Zhang F, Sheng L. Reliability and validity of a Chinese version of the HADS for screening depression and anxiety 
in psycho-cardiological outpatients. Comp Psychiatry (2014) 55:215-20. doi: 10.1016/j.comppsych.2013.08.012

20. Wang W, Bian Q, Zhao Y, Li X, Wang W, Du J, et al. Reliability and validity of the Chinese version of the Patient Health Questionnaire (PHQ-9) in the general population. Gen Hosp Psychiatry (2014) 36:539-44. doi: 10.1016/j.genhosppsych.2014.05.021

21. Shen N, He B. Is the new GOLD classification applicable in China? Lancet Glob Health (2013) 1:e247-8. doi: 10.1016/S2214-109X(13)70064-0

22. Reda AA. Reliability and validity of the Ethiopian version of the hospital anxiety and depression scale (HADS) in HIV infected patients. PLOS ONE (2011) 6:e16049. doi: 10.1371/journal.pone.0016049

23. Kroenke K, Spitzer RL, Williams JB. The PHQ-9: validity of a brief depression severity measure. J Gen Int Med. (2001) 16:606-13. doi: 10.1046/j.1525-1497.2001.016009606.x

24. van der Zwaan GL, van Dijk SE, Adriaanse MC, van Marwijk HW, van Tulder MW, Pols AD, et al. Diagnostic accuracy of the patient health questionnaire-9 for assessment of depression in type II diabetes mellitus and/or coronary heart disease in primary care. J Affect Disord. (2016) 190:6874. doi: 10.1016/j.jad.2015.09.045

25. Das M, Isaakidis P, Van den Bergh R, Kumar AM, Nagaraja SB, Valikayath $\mathrm{A}$, et al. HIV, multidrug-resistant TB and depressive symptoms: when three conditions collide. Glob Health Act (2014) 7:24912. doi: 10.3402/gha.v7.24912

26. Lowe B, Unutzer J, Callahan CM, Perkins AJ, Kroenke K. Monitoring depression treatment outcomes with the patient health questionnaire-9. Med Care (2004) 42:1194-201. doi: 10.1097/00005650-200412000-00006

27. Basu G, Chatterjee C, Singh R, Biswas S. Prevalence of depression in tuberculosis patients: an experience from a DOTS clinic. IJRRMS (2012) 2:14-7.

28. Bestall JC, Paul EA, Garrod R, Garnham R, Jones PW, Wedzicha JA. Usefulness of the Medical Research Council (MRC) dyspnoea scale as a measure of disability in patients with chronic obstructive pulmonary disease. Thorax (1999) 54:581-6. doi: 10.1136/thx.54.7.581

29. Ugarte-Gil C, Ruiz P, Zamudio C, Canaza L, Otero L, Kruger $\mathrm{H}$, et al. Association of major depressive episode with negative outcomes of tuberculosis treatment. PLoS ONE (2013) 8:e69514. doi: 10.1371/journal.pone.0069514

30. Issa BA, Yussuf AD, Kuranga SI. Depression comorbidity among patients with tuberculosis in a university teaching hospital outpatient clinic in Nigeria. Mental Health Fam Med. (2009) 6:133-8.

31. Masumoto S, Yamamoto T, Ohkado A, Yoshimatsu S, Querri AG, Kamiya Y. Prevalence and associated factors of depressive state among pulmonary tuberculosis patients in Manila, The Philippines. Int J Tuberculosis Lung Dis. (2014) 18:174-9. doi: 10.5588/ijtld.13.0335
32. Carter GC, Cantrell RA, Victoria Z, Haynes VS, Phillips G, Alatorre CI, et al. Comprehensive review of factors implicated in the heterogeneity of response in depression. Depress Anxiety (2012) 29:340-54. doi: 10.1002/da. 21918

33. Martinez Rivera C, Costan Galicia J, Alcazar Navarrete B, Garcia-Polo C, Ruiz Iturriaga LA, Herrejon A, et al. Factors associated with depression in COPD: a multicenter study. Lung (2016) 194:335-43. doi: 10.1007/s00408-0169862-7

34. Wood AM, Boyce CJ, Moore SC, Brown GD. An evolutionary based social rank explanation of why low income predicts mental distress: a 17 year cohort study of 30,000 people. J Affect Disord. (2012) 136:882-8. doi: 10.1016/j.jad.2011.09.014

35. Mykletun A, Overland S, Aaro LE, Liabo HM, Stewart R. Smoking in relation to anxiety and depression: evidence from a large population survey: the HUNT study. Eur Psychiatry (2008) 23:77-84. doi: 10.1016/j.eurpsy.2007.10.005

36. Bellos S, Skapinakis P, Rai D, Zitko P, Araya R, Lewis G, et al. Longitudinal association between different levels of alcohol consumption and a new onset of depression and generalized anxiety disorder: Results from an international study in primary care. Psychiatry Res. (2016) 243:30-4. doi: 10.1016/j.psychres.2016.05.049

37. Han JK, Im JG, Park JH, Han MC, Kim YW, Shim YS. Bronchial stenosis due to endobronchial tuberculosis: successful treatment with self-expanding metallic stent. AJR Am J Roentgenol. (1992) 159:971-2. doi: 10.2214/ajr.159.5.1414809

38. Kashyap S, Mohapatra PR, Saini V. Endobronchial tuberculosis. Ind J Chest Dis Allied Sci. (2003) 45:247-56. doi: 10.21037/jtd.2016.12.73

39. Economou M, Madianos M, Peppou LE, Patelakis A, Stefanis CN. Major depression in the era of economic crisis: a replication of a cross-sectional study across Greece. J Affect Disord. (2013) 145:308-14. doi: 10.1016/j.jad.2012.08.008

Conflict of Interest Statement: The authors declare that the research was conducted in the absence of any commercial or financial relationships that could be construed as a potential conflict of interest.

Copyright (C) 2018 Wang, Li, Zhang, Zhang, Chen, Xu, Fu, Wang, Kang and Hou. This is an open-access article distributed under the terms of the Creative Commons Attribution License (CC BY). The use, distribution or reproduction in other forums is permitted, provided the original author(s) and the copyright owner(s) are credited and that the original publication in this journal is cited, in accordance with accepted academic practice. No use, distribution or reproduction is permitted which does not comply with these terms. 